\title{
Heat distribution at joints of subjects with musculoskeletal and neuromuscular dysfunctions
}

\author{
Onigbinde Ayodele Teslim ${ }^{1}$, Fadare Oluseye Emmanuel ${ }^{1}$, Akindoyin Olubukola ${ }^{1}$, Tarimo Nesto ${ }^{2}$ \\ ${ }^{1}$ Department of Medical Rehabilitation, College of Health Sciences, Obafemi Awolowo University, Ile-Ife, Osun State, Nigeria \\ ${ }^{2}$ Malawi Against Physical disabilities, P.O.Box 256, Blantyre, Malawi
}

Email address:

ayotesonigbinde@yahoo.co.uk (A. T. Onigbinde)

\section{To cite this article:}

Onigbinde Ayodele Teslim, Fadare Oluseye Emmanuel, Akindoyin Olubukola, Tarimo Nesto. Heat Distribution at Joints of Subjects with Musculoskeletal and Neuromuscular Dysfunctions. Clinical Medicine Research. Vol. 3, No. 3, 2014, pp. 74-79.

doi: $10.11648 /$ j.cmr.20140303.15

\begin{abstract}
Body temperature is being speculated to be accurate for diagnosis and also monitor chronicity of diseases. Most studies on skin temperature are obsolete and were mostly done in Europe, and racial differences have been noted to have profound effect on human health. The primary objective of this study was to compare the temperatures on the affected and unaffected sides of selected patients with neuromuscular and musculoskeletal dysfunctions. Sixty-nine patients with neuromuscular and musculoskeletal disorders participated in the study. Temperatures were taken at both the pathologic and non-pathologic joints. Data obtained were analysed using descriptive and inferential statistics of paired t-test at 0.05 alpha levels. The results showed no significant difference between axillary, elbow, wrist, knee and ankle joints temperature of the pathologic and non-pathologic upper extremities of subjects with neurological conditions A mean skin temperature difference of $0.29{ }^{\circ} \mathrm{C}$ was observed between neuromuscular and musculoskeletal dysfunctions. However, within subjects with musculoskeletal dysfunctions; the skin temperature at the pathologic knee joint was significantly higher than that of the non-pathologic knee joint $(\mathrm{t}=2.43, \mathrm{p}=0.02)$. We concluded that, for patients with neuromuscular dysfunctions; there was a minor but an insignificant decrease in skin temperature of pathologic joints compared to that of non-pathologic joints. The mean skin temperature at the pathologic knee joint of patients with musculoskeletal dysfunctions was significantly higher than that of the non-pathologic knee joint.
\end{abstract}

Keywords: Skin Temperature, Musculoskeletal, Neuromuscular, Diagnosis

\section{Introduction}

There is increasing awareness on the likelihood of using thermodynamic temperature measurements as a tool to assess health status, hence, it is recommended as part of the initial assessment in acute illness in adults; and as guidelines for post-operative management in adults $[1,2,3$, 4]. Pocock and Richards observed that a healthy body maintains its temperature within a narrow range using homeostatic thermoregulation mechanisms [5]. There is variation in reports from different studies, although, $36^{\circ} \mathrm{C}$ $37.5^{\circ} \mathrm{C}$ is acceptable in clinical practice [6].

There are series of methods to measure body temperature. Thomas et al used thermistor probe thermometer to measure joint inflammation in a case of acute synovitis of the knee joint. Infrared thermography (IRT) has been used for the past ten years to measure skin temperature [7]. The use of iButtons has been described in studies on circadian rhythms, sleep and cardiac surgery and it has been noted to be of significant value in laboratory, clinics and home. The advantage of iButtons in surgery research is that they are easily sterilized and wireless so that they do not hinder the surgical procedure [8].

Temperature changes can also be useful in the diagnosis of some joint pathology but there seems to be absence of enough evidence to ascertain this. Poikalainen et al observed that temperature distribution varies at different parts of the body and that it is diagnostics of leg injuries and body surface damages, although, this is in animals [9]. Change in skin temperature is one of the cardinal signs of inflammation. Fevers may be as a result of arthritis such as rheumatoid arthritis, infection and many other medical problems [9]. Horvath and Hollander measured the intraarticular temperature in patients with rheumatoid arthritis with the speculation that it could be used as a guide to the acuteness of inflammation [10]. In an old report of Bacon 
et al, they suggested that mean skin temperature can be used as a measure of disease activity; and that it may be used as a diagnostic tool [11]. They also suggested that it could be used to monitor chronicity of diseases but there is dearth of adequate data to confirm all these speculations. Similarly, most studies on skin temperature are obsolete and are mostly in Europe; and considering racial differences and climatic variations, there is need to know if there is difference between skin temperature of pathologic and non-pathologic joints. The primary aims of this study were to determine the skin temperature of pathologic and non-pathologic joints and to compare skin temperature between the two joints. It was hypothesized that there would be no significant difference in the skin temperature of pathologic and non-pathologic joint.

\section{Materials and Methods}

\subsection{Subjects}

The subjects for this study were 69 patients (both in and out-patients) from four selected hospitals with symptomatic and radiologic evidence of joint pathologies (neuromuscular or musculoskeletal dysfunctions). The main investigator also physically examined each participant to arrive at the same clinical impressions as previously diagnosed by the consultants.

\subsection{Inclusion Criteria}

The subjects who participated must possess a unilateral joint pathology in any of the shoulder, elbow, wrist, knee or ankle joints and might be in-patients or out-patients receiving treatment at the department of Physiotherapy at the selected hospitals. Excluded were patients with bilateral joint affectations, open wounds or skin damage at the affected joints and those who had received cryotherapy or thermal radiation.

\subsection{Sampling Technique}

Patients with neuromuscular (Erb's palsy and hemiplegia) and musculoskeletal dysfunctions (Osteoarthritis, fracture and dislocation) were selected using sample of convenience.

\subsection{Research Design}

The research design was a quasi-experimental design. There was no intervention but the non-pathologic extremities served as control. The purposively selected hospitals are two University Teaching Hospitals, one Federal Medical Centre and one state hospital.

\subsection{Instrumentations}

A Lily pad DEV-08777 temperature sensor was used to measure the skin temperature with minimal errors from the ambient/atmospheric temperature. Methylated spirit (75\% alcohol) was used to sterilize the temperature sensor after each use while cotton wool was used to apply the methylated spirit. Prior to the commencement of the study, the reliability of the temperature sensor was established using 5 apparently healthy subjects. The mean axillary temperature monitored on day 1 and 2 with a test-retest interval of 5 days. The reliability coefficient ( $r$ ) was 0.96 (p $=0.04)$.

\subsection{Procedure}

The Research and ethics committee of the Institute of Public Health, ObafemiAwolowo University, Ile-ife, Osun State, Nigeria granted approval for the study. The purpose and procedures of the research work was also explained to each of the subjects and they all consented to participate.

The patients were placed in comfortable position and the joints to be examined were exposed (both extremities). The instrument was softly cleaned with a cotton wool that has been dipped in methylated spirit. The temperature sensor was placed on the skin and the temperature readings were noted and recorded for the pathologic and non - pathologic joints. The subjects were instructed to remain still as much as possible while the temperature sensor was being fixed. Three recordings were taken for each joint and the average was computed for data analysis. Measurements were taken at the same time of the day to avoid the effect of circadian rhythm.

\subsection{Data Analysis}

The data were analysed using descriptive statistics (mean and standard deviation) and parametric inferential statistics of paired t-test. Paired t-test was used to compare the skin temperature of the pathologic and non-pathologic sides. Mean difference in temperature was also determined.

\section{Results}

A total of 69 patients consented to participate in the study. The result of the study showed that there are $23(33.3 \%)$ male and $46(66.7 \%)$ female. The mean age of the participants was $51.34 \pm 21.25$ years. The mean duration of onset for all conditions was $73.48 \pm 8.70$ weeks. The diagnoses were grouped into Neurologic (Erb'spalsy and hemiparesis) and Musculoskeletal (osteoarthritis, fracture, dislocation) dysfunctions. The frequencies of diagnoses for the patients are presented in Table 1 .

The mean axillary temperature of patients with neurological dysfunction (upper extremity) on the affected side was $36.19 \pm 0.39^{\circ} \mathrm{C}$, while the unaffected side was $36.29 \pm 0.42^{\circ} \mathrm{C}$. The average difference between the axillary temperatures was $0.1^{\circ} \mathrm{C}$. The result showed that there was no significant difference between the axillary temperature of the affected and unaffected upper extremities. Other skin temperatures at different sites in the upper limbs are presented in Table 2.

The mean skin temperature of the knee on the affected side was $31.77 \pm 1.53^{\circ} \mathrm{C}$ while that of the unaffected was $31.74 \pm 1.67^{\circ} \mathrm{C}$ for patients with neurological dysfunction. 
There was also no significant difference in the mean skin temperature of the affected and unaffected lower extremities. Other results are shown in Table 3.

Table 1. Frequency Distribution of Diagnoses

\begin{tabular}{lcc}
\hline Diagnoses & Frequency & Percentage (\%) \\
\hline Erb's palsy & 4 & 5.80 \\
Hemiparesis & 11 & 15.90 \\
Fracture & 17 & 24.60 \\
Dislocation & 4 & 5.80 \\
Osteoarthritis & 30 & 43.50 \\
*Immobilization & 1 & 1.40 \\
Sprain & 1 & 1.40 \\
Stiffness & 1 & 1.40 \\
\hline
\end{tabular}

*Post immobilization stiffness

Table 2. Comparison of the Skin Temperature of Affected and Unaffected Upper Extremities of Patients with Neurological Dysfunctions

\begin{tabular}{lllllll}
\hline Sites & Extremity & $\mathbf{N}$ & $\begin{array}{l}\text { Mean } \\
\text { temperature }\end{array}$ & SD & $\mathbf{t}$ & $\mathbf{p}$ \\
\hline Axilla & Affected & 15 & 36.19 & 0.39 & & \\
& Unaffected & 15 & 36.29 & 0.42 & 0.70 & 0.51 \\
\multirow{2}{*}{ Elbow } & Affected & 15 & 32.33 & 1.21 & & \\
& Unaffected & 15 & 32.38 & 0.84 & 0.24 & 0.82 \\
\multirow{2}{*}{ Wrist } & Affected & 15 & 32.00 & 1.23 & & \\
& Unaffected & 15 & 32.25 & 1.49 & 1.11 & 0.31 \\
\hline
\end{tabular}

Table 3. Comparison of the Skin Temperature of Affected and Unaffected Lower Extremities of Patients with Neurological Conditions

\begin{tabular}{lllllll}
\hline Sites & Extremity & $\mathbf{N}$ & $\begin{array}{l}\text { Mean } \\
\text { temperature }\end{array}$ & SD & T & P \\
\hline Knee & Affected & 11 & 31.77 & 1.53 & & \\
& Unaffected & 11 & 31.40 & 1.67 & 0.80 & 0.94 \\
\multirow{2}{*}{ Ankle } & Affected & 11 & 30.60 & 1.90 & & \\
& Unaffected & 11 & 30.73 & 1.87 & 1.00 & 0.39 \\
\hline
\end{tabular}

The mean axillary temperature on the affected side was $36.33 \pm 0.34^{\circ} \mathrm{C}$ while on the unaffected side was $36.54 \pm$ $0.29^{\circ} \mathrm{C}$ for the subjects with musculoskeletal dysfunctions. The mean difference in axillary temperature was $0.21{ }^{\circ} \mathrm{C}$. There was no significant difference between the axillary temperatures of the affected and unaffected sides $(\mathrm{t}=1.20$, $\mathrm{p}=0.27$ ). The skin temperatures for the elbow and wrist are presented in Table 4.

The mean temperature of the knee joint on the affected side for the subjects with musculoskeletal dysfunctions was $32.17 \pm 1.04^{\circ} \mathrm{C}$ while on the unaffected side was $31.95 \pm 1.10^{\circ} \mathrm{C}$. There was significant difference in the skin temperature of the affected and unaffected knee joint $(t=2.43, p=0.02)$. The skin temperatures for the ankle joints are shown in Table 5.
Table 4. Skin Temperature of Affected and Unaffected Upper Extremities of Patients with Musculoskeletal Conditions

\begin{tabular}{lllllll}
\hline Sites & Temperature & N & Mean & SD & T & P \\
\hline Axilla & Affected & 8 & 36.33 & 0.34 & & \\
& Unaffected & 8 & 36.54 & 0.29 & -1.20 & 0.27 \\
\multirow{2}{*}{ Elbow } & Affected & 8 & 32.29 & 1.37 & & \\
& Unaffected & 8 & 32.76 & 1.27 & -2.06 & 0.07 \\
\multirow{2}{*}{ Wrist } & Affected & 8 & 32.03 & 1.44 & & \\
& Unaffected & 8 & 32.66 & 1.32 & -2.02 & 0.08 \\
\hline
\end{tabular}

Table 5. Skin Temperature of Affected and Unaffected Lower Extremities of Patients with Musculoskeletal Conditions

\begin{tabular}{lllllll}
\hline Sites & Temperature & $\mathbf{N}$ & Mean & SD & T & P \\
\hline \multirow{2}{*}{ Knee } & Affected & 52 & 32.17 & 1.04 & & \\
& Unaffected & 52 & 31.95 & 1.10 & 2.43 & $0.02 *$ \\
\multirow{2}{*}{ Ankle } & Affected & 11 & 31.60 & 0.78 & & \\
& Unaffected & 11 & 31.74 & 0.89 & -1.13 & 0.29 \\
\hline
\end{tabular}

Key: * - Significance at $0.05 \alpha$-level

Table 6. Skin temperature differences between groups (Affected Sides)

\begin{tabular}{llll}
\hline Sites & $\begin{array}{l}\text { Neuromuscular } \\
\text { Temperature }\end{array}$ & $\begin{array}{l}\text { Musculoskeleta } \\
\text { I temperature }\end{array}$ & $\begin{array}{l}\text { Mean } \\
\text { difference }\end{array}$ \\
\hline Aff: Knee & 31.87 & 32.16 & 0.29 \\
Ankle & 31.08 & 31.49 & 0.41 \\
Unaff: Knee & 32.19 & 31.86 & 0.33 \\
Ankle & 31.37 & 31.23 & 0.15 \\
\hline
\end{tabular}

The number of patients with musculoskeletal conditions at the knees and ankles are 51, while the neuromuscular group participants are 11. The lopsidedness in the number of participants in the 2 groups (51 to 11 ) was statistically inappropriate, hence, mean temperature difference was computed. The mean temperature difference (on the affected sides of patients with neuromuscular and musculoskeletal) on the knees was $0.29^{\circ} \mathrm{C}$. The information is presented in Table 6 . The mean temperature difference (on the unaffected sides of patients with neuromuscular and musculoskeletal) on the knees was $0.33^{\circ} \mathrm{C}$ (Table 6).

The results obtained revealed that there was correlation between the skin temperature of the affected knee and the unaffected knee. It also showed there was a significant correlation between the affected wrist and the affected elbow (at $\mathrm{p}<0.05$ ). There was no correlation between the period of onset and the axillary temperature on the affected side (at $\mathrm{p}<0.05$ ). There was also no significant correlation between the period of onset and diagnosis. Other results on correlations are presented in Table 7

\section{Discussion}

It is vital to measure temperature accurately as it has an impact on diagnosis and treatment [3]. The study observed that almost all the joints of participants have temperature 
that falls below normal body temperature excluding the axillary temperature. A range of $30.60^{\circ} \mathrm{C}$ to $32.33^{\circ} \mathrm{C}$ was observed for all the affected joints and there was a descendant drop in skin temperature caudally. This finding corroborated that of Poikalainen et al who observed that temperature of legs was lowest at the hoofs and highest at the coronary band [4].

Table 7. Pearson Moment Correlation Coefficient of the Relationship All Variables

\begin{tabular}{|c|c|c|c|c|c|c|c|c|c|c|c|c|c|}
\hline & Age & Onset & Axaff & Axunn & Elbaff & Elbunaff & Wrstaff & Wrstunn & Knaff & Knunn & Ankaff & Ankunn & Diag \\
\hline Age & 1 & & & & & & & & & & & & \\
\hline \multicolumn{14}{|l|}{$\mathrm{P}$} \\
\hline Onset & 0.20 & 1 & & & & & & & & & & & \\
\hline $\mathrm{P}$ & 0.25 & & & & & & & & & & & & \\
\hline Axaff & -0.17 & 0.48 & 1 & & & & & & & & & & \\
\hline $\mathrm{P}$ & 0.54 & 0.07 & & & & & & & & & & & \\
\hline Axunn & -0.17 & 0.19 & 0.28 & 1 & & & & & & & & & \\
\hline $\mathrm{P}$ & 0.54 & 0.49 & 0.31 & & & & & & & & & & \\
\hline Elbaff & 0.29 & 0.39 & -0.10 & 0.15 & 1 & & & & & & & & \\
\hline$P$ & 0.30 & 0.15 & 0.72 & 0.59 & & & & & & & & & \\
\hline Elbunaff & 0.38 & 0.30 & -0.14 & 0.30 & $0.85^{* *}$ & 1 & & & & & & & \\
\hline$P$ & 0.17 & 0.27 & 0.62 & 0.28 & 0.00 & & & & & & & & \\
\hline Wrstaff & 0.07 & 0.42 & 0.15 & $0.54 *$ & $0.80 * *$ & $0.60^{*}$ & 1 & & & & & & \\
\hline$P$ & 0.81 & 0.12 & 0.58 & 0.04 & 0.00 & 0.02 & & & & & & & \\
\hline Wrstunn & -0.02 & 0.41 & 0.30 & $0.56^{*}$ & $0.63 * *$ & $0.62 *$ & $0.84^{* *}$ & 1 & & & & & \\
\hline$P$ & 0.95 & 0.13 & 0.27 & 0.03 & 0.01 & 0.01 & 0.00 & & & & & & \\
\hline Knaff & 0.03 & -0.09 & -0.40 & -0.02 & $0.81 * *$ & 0.86 & 0.30 & 0.21 & 1 & & & & \\
\hline$P$ & 0.83 & 0.64 & 0.26 & 0.96 & 0.01 & 0.00 & 0.41 & 0.55 & & & & & \\
\hline Knunn & -0.01 & 0.10 & -0.60 & 0.13 & 0.80 ** & $0.85^{* *}$ & 0.41 & 0.19 & $0.82 * *$ & 1 & & & \\
\hline$P$ & 0.92 & 0.59 & 0.07 & 0.73 & 0.01 & 0.00 & 0.24 & 0.59 & 0.00 & & & & \\
\hline Ankaff & -0.24 & 0.04 & -0.09 & 0.39 & 0.37 & 0.54 & 0.33 & 0.53 & $0.70 * *$ & 0.53 & 1 & & \\
\hline $\mathrm{P}$ & 0.40 & 0.90 & 0.81 & 0.27 & 0.30 & 0.11 & 0.35 & 0.12 & 0.01 & 0.06 & & & \\
\hline Ankunn & -0.07 & 0.15 & -0.18 & 0.43 & 0.49 & $0.63^{*}$ & 0.38 & 0.53 & $0.78^{* *}$ & $0.71 * *$ & $0.95 * *$ & 1 & \\
\hline $\mathrm{P}$ & 0.81 & 0.61 & -0.62 & 0.22 & 0.16 & 0.04 & 0.29 & 0.12 & 0.02 & 0.07 & 0.00 & & \\
\hline Diag & 0.17 & -0.13 & -0.20 & 0.35 & -0.02 & 0.18 & 0.01 & 0.16 & 0.13 & 0.07 & 0.38 & 0.38 & 1 \\
\hline $\mathrm{P}$ & 0.17 & 0.44 & 0.47 & 0.20 & 0.95 & 0.52 & 0.96 & 0.58 & 0.31 & 0.61 & 0.16 & 0.17 & \\
\hline
\end{tabular}

Keys: Diag-diagnoses, ankunn-unaffected ankle, ankaff-affected ankle, knunn-unaffected knee, knaff- affected knee, wrstunn-unaffected wrist, wrstaff- affected wrist, elbunaffunaffected elbow, elbaff-affected elbow, axunn-unaffected axilla, axaff-affected axilla

$*$-significance at $0.05 \alpha$-level, $* *$ significance at $0.01 \alpha$-level

The normal range for core temperature in the literature varies, although $36^{\circ} \mathrm{C}-37.5^{\circ} \mathrm{C}$ is acceptable in clinical practice [6]. Homeostatic thermoregulation system maintains body temperature within a narrow range [5]. It is usually estimated that for every $1^{\circ} \mathrm{C}$ rise in body temperature, there is a $10 \%$ rise in the rate of enzymecontrolled chemical reactions [12]. The cells are destroyed while enzymes are denatured when the temperature goes above $43^{\circ} \mathrm{C}$ and when the temperature decreases, the metabolic rate falls [12].

The findings of this study showed that there were no significant differences in the mean skin temperatures of the affected and unaffected extremities of subjects with neuromuscular dysfunction. Wasner et al observed skin temperature asymmetries between both limbs under resting conditions in most Complex regional pain syndrome type I
(CRPS) patients, although, they referred to the difference as minor [13]. Most hemiparetic patients have often reported symptoms of temperature asymmetry and increased sensitivity to pain on the hemiparetic side while piloerection, a normal response to cold, was noticed only on the contra-lesional side [14].

The mean axillary temperature was averagely lower in patients with neuromuscular dysfunctions. Mulley et al reported that the axillary temperature on the normal side was higher in patients with hemiplegia [15]. Labar et al also reported sudomotor disturbances in stroke patients, these are symptoms suggestive of autonomic dysfunction on one side of the body after stroke, and objective measurements demonstrated the occurrence of sweat, temperature, and skin perfusion asymmetries [16]. Furthermore, Hovarth et al, revealed that quiescent joints 
had sub-normal temperature [17]. There was also a positive correlation of both surface temperature and relevant clinical activity. Naver noted that the symptom of coldness on the contra-lesional side is related to skin vasomotor reflex asymmetry and a lesion of spino-thalamo-cortical pathways and this could be attributed to a disturbance in central processing [14]. Similar trend of indifferences in skin temperatures were observed for patients with musculoskeletal dysfunctions in both upper and lower extremity joints excluding that of the knee joint. The skin temperature of affected knee joint was significantly higher than the unaffected among patients with musculoskeletal dysfunctions. This report corroborated that of Salisbury et al [18]. Their study showed an "abnormal" thermal pattern in joints of patients who had clinical evidence of synovitis and this is suggestive of a characteristic difference between normal and abnormal joints in orthopeadic cases. Similarly, Poikalainen et al reported that skin injuries are clearly distinguishable with an obvious higher temperature [4]. In their study, the injury region temperature was $32.8^{\circ} \mathrm{C}$ while the surrounding normal skin temperature is $27.4-28.2^{\circ} \mathrm{C}$ in animal. The high temperature observed in this our current study might be a sign of continuing inflammatory reaction at the pathologic knee joint, being a weight bearing joint. Functional activities such as squatting and ambulation may continue to trigger off an inflammatory process, thereby, increasing warmness at the joint.

The mean temperature difference on the affected sides of patients with neuromuscular and musculoskeletal on the knees was $0.29^{\circ} \mathrm{C}$ while it was $0.41^{\circ} \mathrm{C}$ at the ankle joint with those having orthopeadic dysfunctions showing higher value, this difference could be taken as very minor. Naver et al found that the contra-lesional site was lowered by $0.4^{0} \mathrm{C}$ in patients with hemispheric lesions [14]. It is noteworthy that there is reduced muscle activity and blood flow in patients with neuromuscular dysfunctions (erb's palsy and hemiplegia) who are participants in this study while there is increased activity in the normal contra-lateral side. Body temperature increases as a result of activity [19]. The working muscles on the non-pathologic side are responsible for the increase in heat production, but the body's ability to retain or dissipate heat and the external environment also play a role in how high the core temperature rises [20]. Kim et al studied progression in skin temperature following sciatic nerve injuries of a rat [21]. They noted that skin temperature on the injured area after sciatic nerve injury was influenced by the functional status of the involved muscle. Measurement of skin temperature can differentiate mild peripheral nerve injury from moderate-to-severe injuries, although this was reported to have limited clinical significance [21].

Literature review showed inconsistencies in different reports on skin temperature, although, symptoms interpreted as unilateral disturbances of autonomic function, such as coldness, dryness, sweating, and trophic changes, are well known but incompletely understood in clinical problems after stroke $[14,22]$. Conversely, patients who had musculoskeletal dysfunctions displayed a different temperature pattern. The extremities of the patients with orthopaedic conditions exhibited higher skin temperature. It revealed a significant correlation between the temperatures on the affected and unaffected knee joints.

We observed that there was significant correlation between the skin temperature of the affected knee and the unaffected knee; and between the affected wrist and the affected elbow. However, there was no correlation between the period of onset and the axillary temperature on the affected side. There was also no significant correlation between the period of onset and diagnoses. Labar et al (1988), however, reported a positive correlation of both surface temperature and relevant clinical activity.

\section{Conclusion}

We concluded that there was a minor but insignificant decrease in skin temperature of pathologic joint compared to that of non-pathologic joints of patients with neuromuscular dysfunctions. It was concluded that the mean skin temperature at the pathologic knee joint of patients with musculoskeletal dysfunctions was significantly higher than that of the non-pathologic knee joint. Our finding is suggestive that skin temperature can be used to monitor progression in patients with knee impairments. The small sample size and disparity in the number of patients with neuromuscular and musculoskeletal dysfunctions might be limitations of this study. Furthermore, this study did not take into consideration the effects of handedness and leggedness, hence, this was a pilot investigations.

\section{References}

[1] Scottish Intercollegiate Guidelines Network. Postoperative Management in Adults: a Practical Guide to Postoperative Care for Clinical Staf. Edinburgh: SIGN, 2004, www.sign.ac.uk/pdf/sign77.pdf

[2] National Institute for Health and Clinical Excellence (2007). Acutely Ill patients in Hospital: Recognition of response to acute Illness in Adults in Hospital, London. NICE, www.nice.org.uk/CG50.

[3] Nursing Practice educator. Measuring body temperature 2012 Nursing Times 06.11.12 / Vol 108 No 45 / www.nursingtimes.net. Accessed on the $14^{\text {th }}$ May 14, 2014

[4] Poikalainen V, J. Praks, I. Veermäe and E. Kokin. Infrared temperature patterns of cow's body as an indicator for health control at precision cattle farming. Agronomy Research Biosystem Engineering Special Issue 1, 187-194, 2012

[5] Pocock G, Richards C (2009) The Human Body: an Introduction for the Biomedical and Health Sciences. New York, NY: Oxford University Press

[6] Childs C. Maintaining body temperature. In: Brooker C, Nicol M (eds) Alexander's Nursing, 2011. Accessed on the $14^{\text {th }}$ May 14,2014 
[7] Thomas D, Ansell BM, Smith DS Isaacs RJ http://www. ncbi.nlm.nih gov/pubmed/ 73610271980. Accessed on the $14^{\text {th }}$ May 14,2014

[8] Wouter D van Marken Lichtenbelt, Hein A.M. Daanen, Loek Wouters, Rolf Fronczek, Roy J.E.M. Raymann d Natascha , M.W.Severens f, Eus J.W. Van Someren. Evaluation of wireless determination of skin temperature using iButtons. Physiology \& Behavior 88 (2006) 489-497

[9] Nield LS, Kamat D. Fever In: Kliegman RM, Behrman RE, Jenson HB, Stanton BF. Nelson textbook of paediatrics, $19^{\text {th }}$ eds. Philadephia, PA, Elsevier DSaunders; 2011: 896.

[10] Horvath S M, Hollander J L, 1949. Intra-articular temperature as a measure of a reaction. J Clin Invest; 28: 469-73.

[11] Bacon PA, Collins AJ, Ring EFJ, Cosh JA, Thermography in the assessment of inflammatory arthritis. Clin Rheum Dis, 1976, 2: 51-65

[12] Marieb E, Hoehn K (2010) Human Anatomy and Physiology with Interactive Physiology 10-System Suite. New York, NY: Pearson Publishing.

[13] Wasner G, Schattschneider J, Baron R. Skin temperature side differences--a diagnostic tool for CRPS?Pain. $2002 \mathrm{Jul}$ $98(1-2): 19-26$

[14] Naver Hans, Christian Blomstrand, Sven Ekholm, Christer Jensen, Thomas Karlsson, B. Gunnar Wallin, 1995. Autonomic and Thermal Sensory Symptoms and Dysfunction After Stroke. American stroke association, www.m.stroke.ahajournals.org. Accessed on $14^{\text {th }}$ May 2014.

[15] Mulley G. Axillary temperature differences in hemiplegia. Postgraduate Medical College, 1980, 56, 248.
[16] Labar DR, Mohr JP, Nichols FT, Fenwick TN, Tatemichi. Unilateral hyperhydrosis after cerebral infarction. Neurology, 1988, 38:1679 - 1682 .

[17] Horvath S M, Hollander J L, 1949. Intra-articular temperature as a measure of joint reaction. J Clin Invest; 28: 469-73.

[18] Salisbury Richard S, Graham Parr, Malcolm De Silva, Brian L.Hazzleman and Page-Thomas. Heat distribution over normal and abnormal joints: thermal pattern and quantification. Ann Rheu Dis, 1983, 42, 494-499

[19] Korthuis RJ, San Rafael (CA), 2011.Skeletal Muscle Circulation: Exercise Hyperemia and Regulation of Tissue Oxygenation during Muscular Activity. Morgan and Claypool Life Sciences, 2011, www.ncbi.nlm.nih.gov/book. Accessed on the $14^{\text {th }}$ May 14, 2014.

[20] Miller J. Why does body temperature increase during exercise. Livestrong.com, 2013. Accessed on the $14^{\text {th }}$ May 14,2014

[21] Kim MS, Seo DH, Lim MH, Kim TU, Lee SJ, Hyun JK. Skin temperature changes following sciatic nerve injury in rats. J Neurotrauma. 2012 Dec 10; 29 (18):2738-47.

[22] Oliver Herrmann, Victoria Tarabin, Shgeaki Suzuki, Nicholas Attigah, Irinel Coerea, Armin Schneider, Johannes Vogel, Simeon Prinz, Stefan Schwab, Hannah Monyer, Frank Brombacher, Markus Schwaninger. Regulation of body temperature and neuroprotection by endogeniousinterleukin-6in cerebral ischemia. Hourn of cerebral blood flow and metabolism, 2003, 23, 406-415 